\title{
Empirical Analysis of Influencing Factors of Commercial Bank Loan Services Targeting New Agricultural Management Entities - Study of China's Shangyu District and Huangyan District
}

\author{
Tu Xueyu" ${ }^{1,}$, Chu Xiang ${ }^{2}$ \\ ${ }^{1}$ College of Economics and Management, Zhejiang University of Technology, Hangzhou, P.R. China \\ ${ }^{2}$ College of Science, Zhejiang University of Technology, Hangzhou, P.R. China
}

\section{Email address:}

shirleytutu@126.com (Tu Xueyu),sir.caoye@gmail.com (Chu Xiang)

*Corresponding author

\section{To cite this article:}

Tu Xueyu, Chu Xiang. Empirical Analysis of Influencing Factors of Commercial Bank Loan Services Targeting New Agricultural Management Entities - Study of China's Shangyu District and Huangyan District. Science Innovation. Vol. 4, No. 3, 2016 , pp. 146-150. doi: $10.11648 /$ j.si.20160403.15

Received: April 20, 2016; Accepted: June 4, 2016; Published: June 11, 2016

\begin{abstract}
At present, the financing difficulty of new agricultural management entities is increasingly outstanding, while bank financing acts as an important method to solve this problem. According to commercial bank services, this paper carried out an empirical analysis of influencing factors of new agricultural management entities' financing, based on Logistic model. The analysis results show that several factors have effects on the new agricultural management entities' satisfaction of agricultural loan. The factors include the type of new agricultural management entities, the degree of familiarity towards financing services, the requirements of mortgage and guarantee, the diversity of financing products, the convenience of application, the loan limit, and the political and financial supports of government. As a conclusion, promoting urban credit system construction with two-right mortgage, agricultural loaning service networking and research of pertinent agricultural loaning products will help solve this financing difficulty.
\end{abstract}

Keywords: New Agricultural Management Entities, Agricultural Loan, Logistic Model

\section{商业银行面向新型农业经营主体的农贷服务影响因素实证研究 一以中国上虞黄岩为例}

屠雪瑜 ${ }^{*}$, 储翔 $^{2}$

${ }^{1}$ 经贸管理学院, 浙江工业大学, 杭州, 中国

${ }^{2}$ 理学院, 浙江工业大学, 杭州, 中国

邮箱

shirleytutu@126. com（屠雪瑜）, sir. caoye@gmail.com（储翔）

摘要: 现阶段, 新型农业经营主体 “融资难” 现象突出, 而银行融资是解决其资金问题的重要手段。本文利用Logistic 模型对商业银行面向新型农业经营主体的农贷服务影响因素进行了实证分析，发现新型农业经营主体的类型、对银行 贷款业务的了解程度、抵押品与担保人的要求、金融产品、贷款便利性、贷款额度、政府政策与资金支持等因素都会 
影响新型农业经营主体对银行农贷的满意度。据此，应推动农村信用体系建设；推进 “两权” 抵押贷款; 推动农贷服 务网络化; 加快特色农贷产品的研发。

关键词：新型农业经营主体，银行农贷，Logistic模型

\section{1. 引言}

中国的经济转轨对农业发展提出了新的要求, 传统农 业逐步向现代农业转型。新型农业经营主体是推动农业现 代化的重要驱动力，但目前正遭受着 “融资难”的困扰。 银行作为资金活动的中枢神经, 在中国的金融机构中有着 举足轻重的地位, 对解决新型农业经营主体的 “融资难” 问题有着重要作用。然而, 出于信息不对称、交易成本等 原因, 银行对新型农业经营主体的支持力度不足。中国的 银行应加紧创新农贷服务, 为新型农业经营主体提供有效 的金融支持。

本文选取了中国绍兴市上虞区与台州市黄岩区的新 型农业经营主体作为研究对象, 采用访谈法进行了实地调 查。在对访谈结果进行整理与数据处理后, 选用了 Logistic模型对商业银行面向新型农业经营主体的农贷 服务影响因素进行了实证研究, 并根据实证分析结果提出 了改善商业银行农贷服务的对策建议。

\section{2. 文献综述}

随着融资难问题的突出, 许多学者对新型农业经营主 体的金融支持开展了研究。Steve Boucher 和 Catherine Guirkinger（2007） ${ }^{[1]}$ 认为发展中国家的农村地区抵押资 产稀少且保险市场不成熟, 抵押品防止 “非价格分配” 的 有效性因此受到了限制。József Varga 和 Zoltán Sipiczki （2015） ${ }^{[2]}$ 指出国家必须调动私人资源与公共 资源, 发展贷款技术, 与此同时, 银行（包括国有与民营） 以及其他金融中介机构必须在更大程度上参与农村发展 从而缓解农业企业的融资困境, 刺激生产投资, 发展多功 能的农村经济。Eduardo Rodrigues de Castro 和 Erly Cardoso Teixeira（2012） ${ }^{[3]}$ 认为当农民面临预算限制并 且没有选择个人贷款时，政府的农村信贷计划可能是有效 的, 它能让农民购买更多的物资, 增加产出量。Ayyagari (2010） ${ }^{[4]}$ 等人认为是银行融资（而并不是非正规融资） 促进了中国企业的成长，尤其是对于那些中国农村地区的 小型企业和以家庭为基础的农业企业而言。汪艳涛, 高强 与荷露峰 $(2014){ }^{[5]}$ 通过实证研究说明了不同金融支持方 式对新型农业经营主体的影响效果存在差异。王曙光 (2015) ${ }^{[6]}$ 指出为了能让新型农业经营主体有效获得金融 服务, 必须加紧微型金融服务创新。桂泽发, 吴蔚蓝, 谭 文洁与盖振暗（2014） ${ }^{[7]}$ 发现现有农村金融服务中农民缺 乏有效抵押品, 抵押担保制度尚不完善等问题比较突出。 夏雪 $(2015)^{\left[{ }^{[8]}\right.}$ 在新型农业经营主体的金融供给现状上发 现银行类金融机构在农业贷款方面的投入力度明显不足。 林乐芬和法宁 (2015) ${ }^{[9]}$ 研究了新型农业经营主体的银行 融资障碍因素。丁荣 (2014) ${ }^{[10]}$ 运用SWOT分析法提出了针
对新型农业经营主体的银行服务营销策略。江维国与李立 清（2015） ${ }^{[11]}$ 认为具有交易成本低, 贷款便利等优点的互 联网金融是新型农业经营主体解决贷款难问题的新途径。 然而, 目前针对其银行融资的研究还比较少, 特别是关于 实证分析方面的研究。

\section{3. 研究模型}

当被解释变量是离散变量且有多种选择时, 属于多元 离散选择问题。由于本文被解释变量是新型农业经营主体 对银行农贷的满意程度, 可以按照满意程度依次变大的灵 活性进行排序, 所以有序因变量模型适用于农贷服务影响 因素的实证研究。

同二元选择模型一样, 我们可以考虑潜在变量 $Y_{i}^{*}$ 的值 取决于一组自变量 $X_{i}$, 即

$$
Y_{i}^{*}=X_{i} \beta+u_{i}, i=1,2,3, \ldots, N
$$

上式中, $X_{i}$ 是影响潜在变量的一组解释变量, $\beta$ 为未 知系数, $u_{i}$ 是独立同分布的随机变量, 设 $Y_{i}$ 有 $0,1,2, \ldots, M$ 等 $M+1$ 个取值, 观察到的 $Y_{i}$ 由 $Y_{i}^{*}$ 决定, 即如果连续性随机 变量 $Y_{i}^{*}$ 超过某个临界值 $c$, 则对应 $Y_{i}$ 的一个确定性选择。 两者的关系是:

$$
Y_{i}=\left\{\begin{array}{l}
0, Y_{i}{ }^{*} \leq c_{1} \\
1, c_{1}<Y_{i}{ }^{*} \leq c_{2} \\
2, c_{2}<Y_{i}{ }^{*} \leq c_{3} \\
\cdots \cdots \\
M, c_{M}<Y_{i}{ }^{*}
\end{array}\right.
$$

设 $u_{i}$ 的分布函数为 $F(x)$, 可以得到以下概率:

$$
\begin{aligned}
& F\left(Y_{i}=0\right)=F\left(c_{1}-X_{i} \beta\right) \\
& F\left(Y_{i}=1\right)=F\left(c_{2}-X_{i} \beta\right)-F\left(c_{1}-X_{i} \beta\right) \\
& \ldots \ldots . \\
& F\left(Y_{i}=M\right)=1-F\left(c_{M}-X_{i} \beta\right)
\end{aligned}
$$

根据不同的分布函数 $F(x)$, 通常可以分为 3 种模型: Probit模型、Logistic模型和Extreme value (极值) 模 型。其中, 当分布函数 $F(x)$ 服从逻辑分布时为Logistic 模型; 当分布函数 $F(x)$ 服从正态分布时为Probit模型。 Probit模型需要对多元正态分布的整体进行评价, 应用比 较有限; Logistic模型的似然函数能够快速可靠地收敛, 计算相对简便。因此, 在有序因变量模型中应用最多的是 Logistic模型。 
本文采用Logistic模型对商业银行面向新型农业经 营主体的农贷服务影响因素进行分析。参数估计方法采用 的是极大似然法, 临界值 $c$ 与 $\beta$ 一起作为参数进行估计。

\section{4. 数据来源与变量选取}

\section{1. 数据来源}

本文于 2015年8月对中国上虞与黄岩的新型农业经营 主体进行了实地调研, 采用的调查方式是访谈法。在两区 农业局、供销合作总社、农经总站等政府部门工作人员的
协助下, 我们顺利地开展了调研工作。调研结束后, 我们 对访谈记录进行了数据处理。

\section{2. 变量选取}

本文的被解释变量是新型农业经营主体对银行农贷 的满意程度, 用 $Y$ 表示。解释变量主要分为三部分, 新型 农业经营主体自身的因素、银行因素以及政府因素, 分别 用 $X 1 \sim X 10$ 表示。

表1 变量选取及变量含义。

\begin{tabular}{lll}
\hline 变量类型 & 变量名称 & 变量含义 \\
\hline 被解释变量 & $Y$ 新型农业经营主体对银行农贷的满意程度 & $0=$ 不满意; $1=$ 二般; $2=$ 满意 \\
解释变量 & $X 1$ 主体类型 & $1=$ 专业大户; $2=$ 农民专业合作社; $3=$ 农业企业 \\
& $X 2$ 经营者学历 & $1=$ 小学及以下; $2=$ 初中; $3=$ 高中; $4=$ 本科及上 \\
& $X 3$ 是否有独立的财务核算体系 & $0=$ 否; $1=$ 是 \\
& $X$ 贷款金额要求 & $1=10$ 万下; $2=10$ 万 -50 万; $3=50$ 万 -100 万; $4=100$ 万 -200 万; \\
& $X$ 是否了解银行贷款业务 & $5=200$ 万 -500 万; $6=500$ 万以上 \\
& $X 6$ 是否有银行可接受的抵押品或担保人 & $0=$ 否; $1=$ 是 \\
& $X 7$ 是否有适合自己的金融产品 & $0=$ 否; $1=$ 是 \\
& $X 8$ 贷款申请过程是否便利 & $0=$ 否; $1=$ 是 \\
& $X$ 能申请到的银行贷款是否能满足融资需求 & $0=$ 否; $1=$ 是 \\
& $X 1$ 政府政策与资金支持 & $0=$ 否; $1=$ 是 \\
& & $1=$ 较差; $2=$ 一般; $3=$ 很好 \\
\hline
\end{tabular}

数据来源: 访谈调查记录整理得到。

\section{5. 实证分析}

本文利用SPSS10.0 软件对上述研究模型进行参数估 计与实证检验, Logistic回归结果如表2所示:

表2 研究模型的实证分析结果。

\begin{tabular}{llll}
\hline 变量 & 系数 & 标准差 & Sig. \\
\hline$X 1$ 主体类型 & 0.818 & 0.601 & $0.042^{* *}$ \\
$X 2$ 经营者学历 & -0.081 & 0.833 & 0.764 \\
$X 3$ 是否有独立的财务核算体系 & - & - & - \\
$X 4$ 贷款金额要求 & 0.225 & 1.225 & 0.388 \\
$X 5$ 是否了解银行贷款业务 & 0.898 & 0.500 & $0.002^{* * *}$ \\
$X 6$ 是否有银行可接受的抵押品或 & 0.880 & 0.527 & $0.002^{* * * *}$ \\
担保人 & 0.898 & 0.500 & $0.002^{* * * *}$ \\
$X 7$ 是否有适合自己的金融产品 & 0.629 & 0.500 & $0.067^{*}$ \\
$X 8$ 贷款申请过程是否便利 & 0.625 & 0.527 & $0.059^{*}$ \\
$X 9$ 能申请到的银行贷款是否能满 & 0.625 \\
足融资需求 & \\
$X 10$ 政府政策与资金支持 & 0.666 & 0.833 & $0.019^{* *}$ \\
\hline
\end{tabular}

注释: $* * *$ 、 $* *$ 、 $*$ 分别为置信度检测在 $1 \% 、 5 \% 、 10 \%$ 的水平上的显著。

（1）新型农业经营主体自身的因素。表2显示, 新型 农业经营主体的“类型”对银行农贷的满意度有正面影响, 表明农业企业对银行农贷的满意度更高, 其次是农民专业 合作社, 最后是专业大户。由此可知银行对不同主体的支 持力度存在差异, 而这与其基本服务对象天然倾向于大的 企业有关。
新型农业经营主体的“学历”未通过显著性水平检验, 这说明经营者的教育背景与其对银行农贷服务的满意度 之间没有明显的关系。在实地访谈调查中, 我们发现新型 农业经营主体的教育水平普遍较高, 高中及以上学历的经 营者占比较大。我们推测在教育背景普遍较好的情况下, “学历” 对新型农业经营主体的银行农贷服务满意度不产 生影响。

在进行实证检验的过程中, 我们剔除了 “是否有独立 的财务核算体系” 这一变量。在输入数据时, 我们发现调 查得到的所有样本都具有独立的财务核算体系, 故而无法 进行Logistic回归, 这同时也说明了该解释变量对新型农 业经营主体的银行农贷服务满意度没有影响。

新型农业经营主体的 “贷款金额要求” 没有通过显著 性水平检验, 这表明新型农业经营主体所需的贷款金额无 论大小, 都不会提高或降低其对银行农贷服务的满意度, 也就是说融资需求较高与较低的经营者们都有可能遭遇 银行贷款难的情况。

（2）银行因素。“是否了解银行贷款业务” 与银行 农贷的满意度呈正相关关系。新型农业经营主体越了解银 行的农贷服务, 往往对贷款的要求与流程更为熟悉, 获得 贷款的可能性也越大, 满意度也就越高。这说明银行应该 加大对其贷款业务与产品的宣传力度, 提高新型农业经营 主体对农贷服务的认识度。

“是否有银行可接受的抵押品或担保人”与银行农贷 服务的满意度呈正相关关系。当新型农业经营主体拥有银 行可接受的抵押品或担保人时, 除了信用贷款外还可以进 
行抵押贷款，其对银行农贷服务的满意度提高。而当其没 有相关抵押品或担保人时, 获得贷款的难度也会增大, 满 意度下降。这说明银行应在抵押物与担保制度上进行创新, 例如积极推进 “两权” 抵押贷款等。

“是否有适合自己的金融产品”与银行农贷服务的满 意度呈正相关关系。如果银行的贷款产品符合新型农业经 营主体的融资要求, 那么其更愿意进行银行贷款, 满意度 也自然会提高。因此, 银行应该针对新型农业经营主体的 要求来设计相对应的金融产品。

“贷款申请过程是否便利”与银行农贷服务的满意度 呈正相关关系。贷款的申请手续越简便, 交易成本越低, 申请人对银行服务的满意度也就越高。这说明银行应尽量 简化申请手续, 减少贷款审查的时间, 提高工作效率从而 提高申请人的贷款便利性。

“能申请到的银行贷款是否能满足融资需求”与银行 农贷服务的满意度呈正相关关系。当新型农业经营主体能 够从银行申请到期望的贷款金额时, 其对贷款的满意度会 上升。然而, 在实地访谈调查中我们发现部分新型农业经 营主体从银行申请到的贷款并不能完全满足他们的融资 需求，这表明银行对其资金支持力度尚欠加强。

（3）政府因素。“政府政策与资金支持”与银行农 贷服务的满意度呈正相关关系。在实地访谈中, 我们发现 规范的大型合作社等新型农业经营主体 (例如省级示范性 农民专业合作社）更容易得到政府的政策支持与资金补助， 而这些规模较大的经营主体也更容易获得银行贷款。因此, 政府的扶持作用有利于提高新型农业经营主体对银行农 贷服务的满意度。

\section{6. 对策建议}

根据上述实证分析结果, 我们对商业银行面向新型农 业经营主体的农贷服务提出如下建议:

\section{1 . 推动农村信用体系的建设}

（1）信用评价体系。当地政府可以与银行合作，采 集新型农业经营主体的信用信息, 建立信用档案并进行信 用评价。同时，及时定期更新相关信用数据，在政府、银 行、相关行业间建立信息交换与共享机制。开展“信用村”、 “信用镇”的建设, 根据信用评分来核定农户的信贷额度, 从而方便新型农业经营主体进行信用贷款。

(2)整村授信方式。银行在农村信用体系的基础上， 可以对于信用等级较高的村或镇进行集体授信, 并在贷款 额度与申请上给予一定的优惠。整村授信将一个行政村视 作统一单位实行批发式放贷模式，不仅可以通过农户间的 互相监督来降低银行放贷风险, 提高银行工作效率, 也使 农户缩短了办款时间, 能够更大范围地满足新型农业经营 主体的资金需求。

\section{2. 推进 “两权” 抵押贷款}

（1）土地流转交易平台。政府应扎实推进确权登记 颁证（例如土地确权证、农村土地承包经营权证），加快
土地流转制度的改革, 从而建立起规范合法的农村土地流 转交易平台, 方便 “两权” 抵押贷款的抵押物处置。

（2）统一的土地评估标准。在 “两权” 抵押贷款开 展的初期阶段, 由于农村土地交易市场尚未成熟, 可在政 府的指导下确定农村土地的统一评估标准, 激活土地价值, 使涉农不动产资源具备抵押变现的能力。

\section{3. 推动农贷服务网络化}

(1) 网络营销模式。除了传统的线下营销, 引进网 页介绍、微信公众号推送等互联网营销方式, 进一步加大 对银行农贷产品的宣传力度。同时, 在网络上及时更新各 类农贷产品的信息, 使新型农业经营主体能够快速、准确 地掌握贷款信息, 加深对业务的了解。

（2）网上业务办理。银行可以推出农贷业务的网络 预约与办理（例如手机APP应用），使新型农业经营主体 能够自主借款与还款, 减少办款的等待时间, 缩短办款的 流程, 提高其办款的便利程度。

\section{4. 加快特色农贷产品开发}

（1）合理设计新产品。银行在设计农贷产品前应该 加强对新型农业经营主体发展现状的调研, 不仅要对其具 体的融资需求进行调查, 也要考察其农业生产经营的特点 与资产负债情况, 根据调研结果设计农贷产品, 从而使银 行的农贷服务更适合新型农业经营主体实际的融资需要, 降低其贷款难度。

（2）推出地方特色产品。各地农业具有不同特色, 新型农业经营主体的发展情况也存在差异。银行总行可以 鼓励各地分支行在普适性产品的基础上结合所在地的农 业特色与新型农业经营主体的具体需求向其提出创新建 议, 从而在分支行推出具有各地特色的农贷产品, 避免普 适性产品的单一性。

\section{7. 结论}

本文经过实证研究发现，在新型农业经营主体、银行 与政府三者中银行因素的影响最大, 尤其是对银行贷款业 务的了解程度、抵押品与担保人的要求、金融产品的适用 性这三个变量。因此, 银行应该着重加强农贷业务的推广 力度, 改进对抵押品与担保人的范围要求, 并且根据新型 农业经营主体的实际需求创新金融产品。

本文在进行实地调研时, 由于经费、人员等因素限制, 无法进行大范围的随机抽样, 并且没有讨论部分观测指标 对因变量的影响, 实验结果可能会存在一定误差。在未来 研究中可以探讨其他因素对因变量的影响。

\section{致谢}

本文为浙江省大学生科技创新活动计划 (新苗人才计 划）《面向新型农业经营主体的金融服务创新研究一以浙 江基地型特色农业为例》（2015R403021）的阶段性成果 之一。 


\section{参考文献}

[1] Steve Boucher and Catherine Guirkinger. Risk, Wealth, and Sectoral Choice in Rural Credit Markets [J]. American Journal of Agricultural Economics, 2007, $89(04)$ : $991-1004$.

[2] József Varga and Zoltán Sipiczki. The Financing of the Agricultural Enterprises in Hungary Between 2008 and 2011 [J]. Procedia Economics and Finance, 2015, 30: $923-931$.

[3] Eduardo Rodrigues de Castro and Erly Cardoso Teixeira. Rural Credit and Agricultural Supply in Brazil [J]. Agricultural Economics, 2012, 43(03): $293-301$.

[4] Ayyagari, M., Demirgu “ c-Kunt, A., and Maksimovic, V. Formal versus Informal Finance: Evidence from China [J]. Review of Financial Studies, 2010, 23 (8) : 3048 3097.

［5］汪艳涛, 高强, 苟露峰. 农村金融支持是否促进新型农业经 营主体培育一理论模型与实证检验 $[J]$. 金融经济学研究, 2014, 29 (05) : 89-98。

[6] 王曙光. 农村金融学 [M]. 第二版. 北京: 北京大学出版社, 2015:178-180。

［7］桂泽发, 吴蔚蓝, 谭文洁, 盖振显. 金融支持新型农业经 营主体发展研究一以甘肃省庆阳市为例 [J]. 开发研究, 2014，(05) :96-99。

[8］夏雪. 金融创新支持新型农业经营主体发展研究 [D]. 安徽： 安徽大学, 2015: 10-12.

［9］林乐芬, 法宁. 新型农业经营主体银行融资障碍因素实证分 析一基于 31 个乡镇 460 家新型农业经营主体的调查 [J]. 四 川大学学报, 2015，(06)：119-128。

[10］丁莹. 新型农业经营主体金融服务探析一基于专业大户、家 庭农场、农民合作社的视角 [J]. 农村金融研究，2014， (06) : 68-71。

[11] 江维国, 李立清. 互联网金融下我国新型农业经营主体的条 件与路径融资模式创新 [J]. 财经科学, 2015, (08) :01-12。 